\title{
Changes of Arterial Pulse (Augmentation Index) in Normotensive Subjects with Family History of Hypertension: Implication in Primary Prevention of Hypertension
}

\author{
Leong HC ${ }^{1}$, Kwok CY Timothy ${ }^{2}$ and Woo KS ${ }^{2 *}$ \\ ${ }^{1}$ Macau Heart Foundation, Macau \\ ${ }^{2}$ Department of Medicines and Therapeutics, The Chinese University of Hong Kong
}

*Corresponding author: KS Woo, Adjunct Professor, Department of Medicines and Therapeutics, 4th Floor, Tsang Shiu Tim

Building, United College, The Chinese University of Hong Kong

ARTICLE INFO

Received: 慧 June 10, 2020

Published: 幽 June 17, 2020

Citation: Leong HC, Kwok CY Timothy, Woo KS. Changes of Arterial Pulse (Augmentation Index) in Normotensive Subjects with Family History of Hypertension: Implication in Primary Prevention of Hypertension. Biomed J Sci \& Tech Res 28(2)-2020. BJSTR. MS.ID.004635.

\section{ABSTRACT}

Introduction: Family history plays an important role in the development of essential hypertension, and increased arterial stiffening is an important pathogenic component. Applanation tonometry is a novel technology for evaluating arterial stiffening.

Subjects and Methods: To evaluate the applicability of applanation tonometry, 143 normotensive subjects (51.7\% male) with family history of hypertension, and 143 sex and age-matched subjects without family history of hypertension were recruited from a hypertension survey involving 5117 subjects in Macau. Blood pressure was measured by conventional cuff sphygmomanometer. Radial artery-derived aortic Augmentation Index (AI) was measured by the sphygmocardiographic machine (SphygmoCor system, Millar pencil strain gauge transducer). Their mean \pm standard deviation and 95\% Confidence Interval (CI) were evaluated.

Results: Their demographic factors were similar between the subjects with family history and those without $(\mathrm{P}>0.5)$. Their blood pressures in both groups increased with age. AI was similar in $15-29$ years group $(\mathrm{P}=0.548)$, but $\mathrm{AI}$ in $30-39$ years with family history $(134.9 \pm 19.8,95 \%$ CI $129.3-140.5 \%)$ and those over 40 years $(139.3 \pm 18.8$, 95\% CI 135.0-143.3\%) were significantly higher than those without family history (125.8 $\pm 19.9,95 \%$ CI $120.2-131.4 \%$ and $133.8 \pm 20.8,95 \%$ CI $129.1-138.5 \%$ respectively) $(\mathrm{P}<0.05)$.

Conclusion: AI is significantly higher in normotensive subjects with family history than those without family history. Measurement of AI may be promoted as indicator of potential risk of hypertension, with implication in primary prevention.

\section{Introduction}

Family history plays an important role in the development of essential hypertension [1]. A study from the hypertension survey of 24,762 subjects in China showed the prevalence of hypertension in subjects with hypertensive family history (either father or mother or both have hypertension) was significantly higher than those without family history [2]. Furthermore, the onset age of hypertension in subjects with hypertensive family history was younger than those without hypertensive family history. It is well known that blood pressure is a quantitative trait controlled by numerous hormonals, neural, and structural changes. Structural changes in large blood vessels in hypertension include medial degenerative changes, which stiffen the arteries and increase the pulse wave velocity. Such degree of vascular stiffening may lead to the development of hypertension. Accordingly, genetic risk factors affecting the rate of increase in vascular stiffening are being considered as a topic of great interest [3]. Sphygmocardiography 
has been utilized to assess the pulse wave form, involving the mathematical derivation of central aortic pulses wave forms from recordings of peripheral pulses [4,5]. We propose a first study, we trust, of changes in human arterial pulse using applanation tonometry in subjects with family history of hypertension, as a noninvasive indicator of arterial stiffening, in the pre-clinical stage.

\section{Subjects and Methods}

5117 Chinese volunteers in the community were enrolled in a hypertension survey. 143 'healthy' subjects with family history of hypertension (either parent has BP $>140 / 90 \mathrm{mmHg}$, or has been prescribed anti-hypertensive treatment) were recruited into the study group, and 143 age and sex-matched 'healthy' subjects without family history, were assigned as the control group. All the subjects were screened for cardiovascular history and physical findings; those with valvular heart disease or chronically treated cardiovascular diseases including hypertension (SBP>140mmHg, DBP $>90 \mathrm{mmHg}$ ) were excluded. Blood pressure was measured by conventional cuff sphygmomanometry. The radial arterial pressure waves by applanation tonometry were recorded by the Sphygmocardiography using a Millar pencil strain gauge transducer (Sphygmocor System, PWV Medical Pty. Australia) after $5 \mathrm{~min}$. resting and at least 2 hour's post-prandial (Figure 1). Radial artery-derived aortic Augmentation Index (AI), as the ratio of systolic augmented wave over pulse pressure of unaugmented wave $\mathrm{x} 100$, were derived and recorded as described previously (Figure 2) [6,7]. The intraobserver variability was $4.5-5.5 \%$ and interobserver variability was $11.2-11.6 \%$, as reported by Kelly and London et al. $[8,9]$ Our local intraobserver variability was $5.5 \%$ and interobserver variability $7.3 \%$.

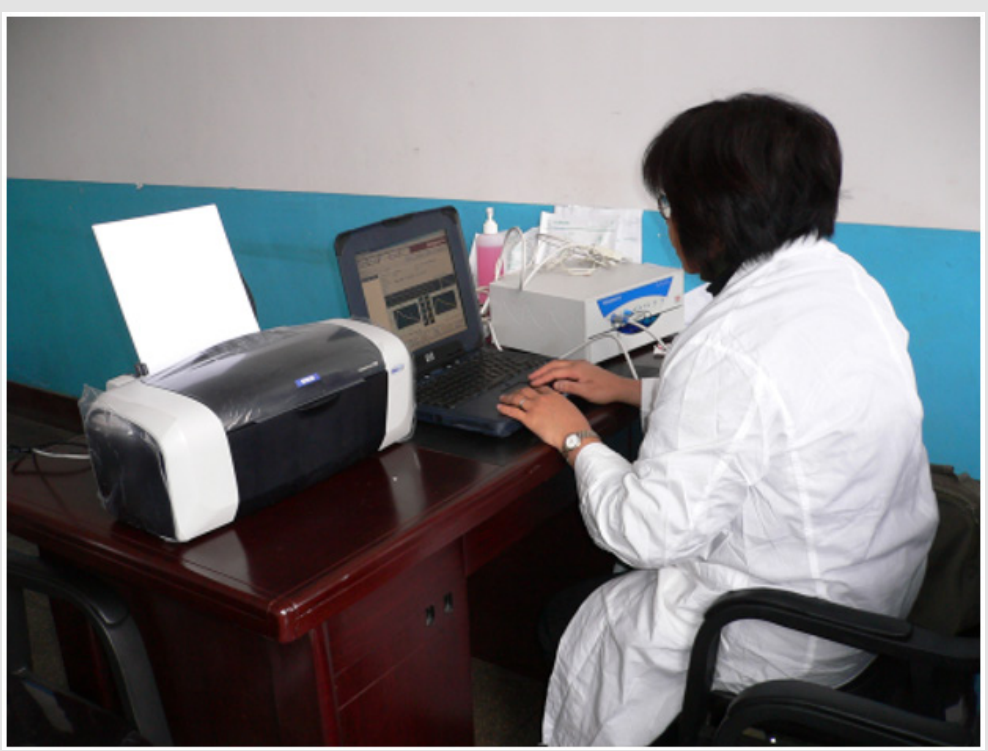

Figure 1: Augmentation index measured by sphygmocor system (central) connected to a printer (left).

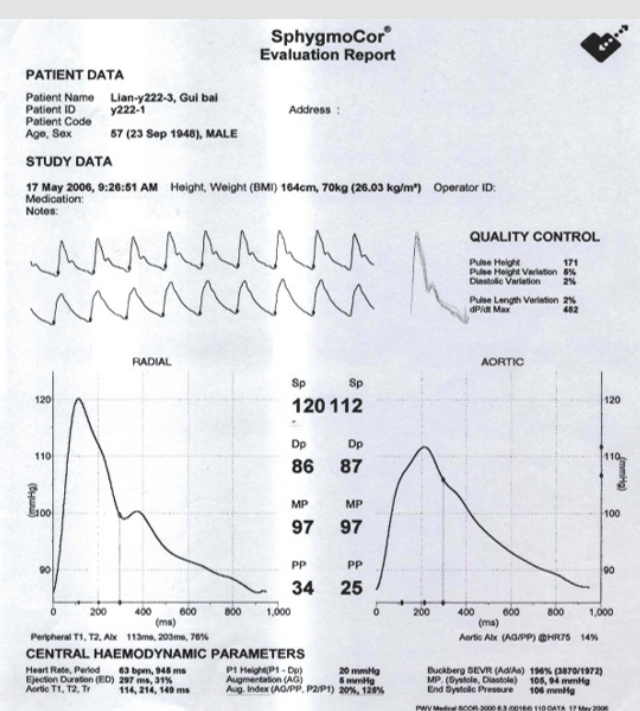

Figure 2: Report of radial artery-derived (left panel) aortic augmentation index (right panel). The index is displayed (middle panel) by underline. 


\section{Statistical Analysis}

Radial artery-derived aortic AI (mean \pm SD and 95\% confidence interval) of the two groups were compared. Statistical analysis was performed using two tails paired Students' test with a significant difference being at the level of ' $2 p^{\prime}<0.05$. All statistical analyses were performed using Microsoft Excel.

\section{Results}

The demographic parameters of both groups were similar (Table 1). In these 286 subjects, there were 107 (37.4\%) men, 179 (62.6\%) women, 38 (13.3\%) subjects in the 15-29 year-old group, 97 (33.9\%) in the 30-39 year-old group, and 151 (52.8\%) in the over 40 year-old group. Other demographic features were similar, including smoking (14-18.2\%), drinking habits (8.4-13.3\%), body mass index (BMI) and body height between the two groups (Table 1). Their mean blood pressure in both groups increased gradually with age $(\mathrm{p}<0.001)$ (Figure 3$)$. In the whole cohort, AI in subjects with family history $(134.0 \pm 20.8,95 \%$ CI 132.3-135.7\%) was significantly higher than the subjects without family history (127.6 $\pm 21.8,95 \%$ CI 124.0-130.6\%) $\mathrm{p}<0.05$ (Figure 4). AI in the 15-29 years old group with family history $(112.1 \pm 16.5,95 \% \mathrm{CI}$ $104.9-119.3 \%)$ were similar to the control group (108.8 \pm 18.4 , $95 \%$ CI $100.5-117.0 \%$ ) $\mathrm{p}=0.548$. However, AI in the $30-39$ years group with family history (134.9 $\pm 19.8,95 \%$ CI $129.3-140.5 \%)$ and those over 40 years (139.3 $\pm 18.8,95 \%$ CI 135.0-143.5\%) were significantly higher than those without family history $(125.8 \pm 19.9$, 95\% CI $120.2-131.4 \%$ and $133.8 \pm 20.8,95 \%$ CI $129.1-138.5 \%$ respectively), $\mathrm{p}<0.05$ (Table 2 ).

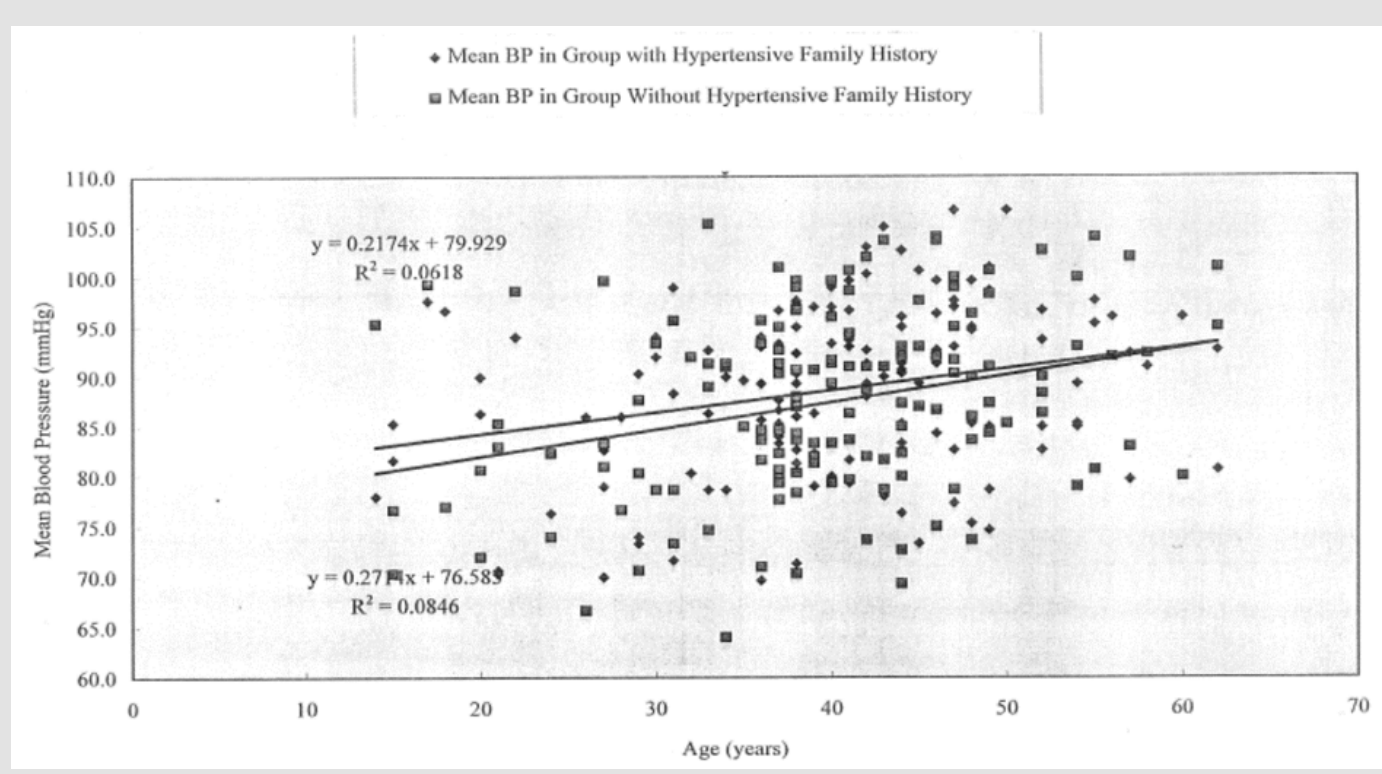

Figure 3: Mean Blood Pressure and Age in Groups with and without of Family History Hypertension.

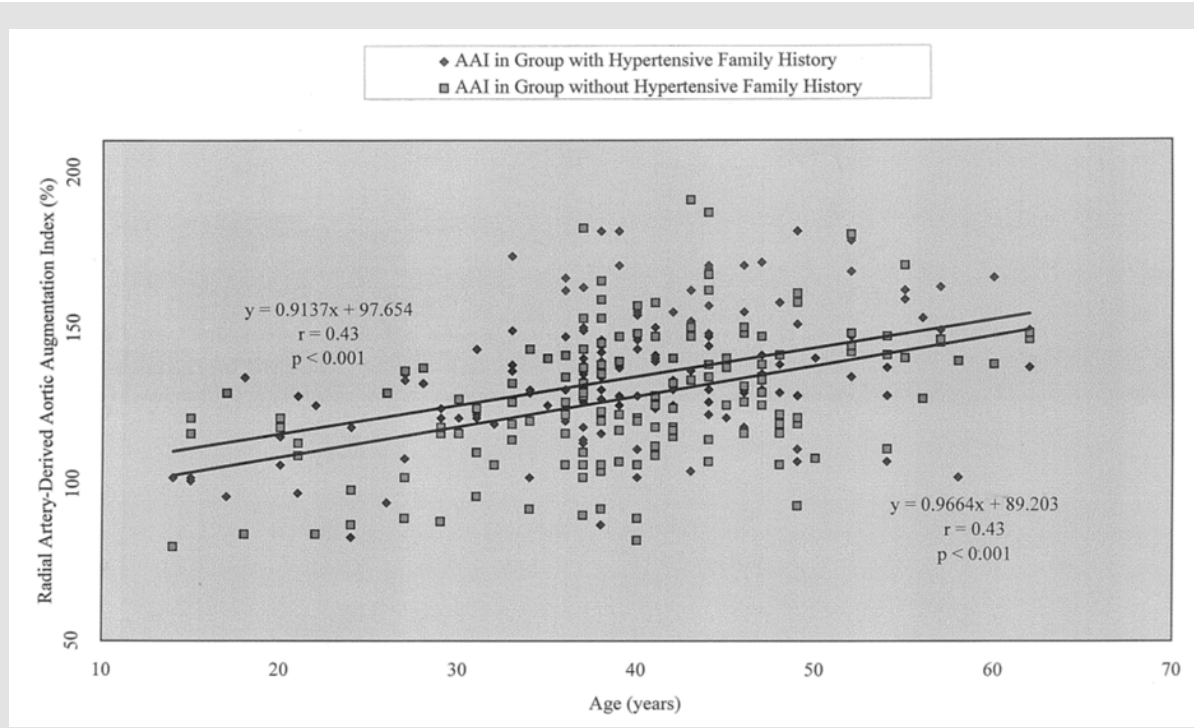

Figure 4: Radial Artery-derived Aortic Augmentation Index and Age in Groups with and Without Hypertensive Family History. 
Table 1: Comparison of Demographic Parameters in Groups with and Without Hypertensive Family History.

\begin{tabular}{|c|c|c|c|}
\hline Parameters & $\begin{array}{c}\text { The group with hypertensive } \\
\text { family history (n=143) }\end{array}$ & $\begin{array}{c}\text { The group without hypertensive } \\
\text { family history (n=143) }\end{array}$ & P-Value \\
\hline SBP (mmHg) & $116.4+11.6$ & $114.8+12.5$ & 0.96 \\
\hline DBP (mmHg) & $74.6+8.0$ & $73.7+8.5$ & 0.94 \\
\hline Height (cm) & $160.7+7.9$ & $160.0+7.3$ & 0.95 \\
\hline BMI & $23.3+4.6$ & $22.9+3.4$ & 0.92 \\
\hline Age (year) & $39.8+9.7$ & $39.8+9.7$ & 1 \\
\hline No. of females & 88 & 88 & 0.75 \\
\hline No. of smokers (\%) & $26(18.2 \%)$ & $20(10 \%)$ & 0.74 \\
\hline
\end{tabular}

Table 2: Radial Artery-Derived Aortic Augmentation Index (\%) (mean \pm SD, 95\% CI) by Age Group.

\begin{tabular}{|c|c|c|c|}
\hline Age (years) & $\begin{array}{c}\text { With Hypertensive Family } \\
\text { History }(\mathbf{n}=\mathbf{1 4 3})\end{array}$ & $\begin{array}{c}\text { Without Hypertensive Family } \\
\text { History (n = 143) }\end{array}$ & \multirow{2}{*}{ P-Value } \\
\hline Whole cohort & $134.0 \pm 20.8$ & $127.6 \pm 21.8$ & $<0.05$ \\
\hline$(95 \% \mathrm{CI})$ & $(132.3-135.7)$ & $(124.0-130.6)$ & $>0.548$ \\
\hline$<29(\mathrm{n}=20)$ & $112.1 \pm 16.5$ & $108.8 \pm 18.4$ & $<0.05$ \\
\hline$(95 \% \mathrm{CI})$ & $(104.9-119.3)$ & $125.8 \pm 19.9$ & $(120.2-131.4)$ \\
\hline$(95 \% \mathrm{CI})$ & $134.9 \pm 19.8$ & $133.8-20.8$ & $<0.05$ \\
\hline
\end{tabular}

\section{Discussion}

Overall control of blood pressure is achieved by a quantitative trait, controlled by numerous hormonals, neural, and other basic mechanisms. A single specific disturbance of these homeostatic mechanisms may not induce hypertension, but the existence of multiple primary defects affecting simultaneously several adaptive mechanisms may lead to hypertension. Genetic influence does not determine only the high or low blood pressure, but the entire range of values [10]. Pickering demonstrated that the first-degree relatives of persons with essential hypertension have higher blood pressures at all ages than the first-degree relatives of those without family history [11]. In a population of 1,989 male industrial workers among 40 and 55 years of age, Ostfeld and Paul showed a continuous distribution of blood pressure, consistent with a polygenetic, but not a single-gene mode of inheritance [12]. Feinleib et al. found monozygotic twins had higher correlation of systolic and diastolic pressure than dizygotic twins [13]. As an instrument of applanation tonometry, Sphygmocardiography is easy to use, minimally timeconsuming and highly reproducible. This noninvasive recording of pulse wave form can be used on large number of subjects and repeatedly on the same subjects.

Previous studies have documented its applicability in evaluating favourable effects on left ventricular afterload by nitroglycerin [14], arterial hemodynamic and ventricular-vascular interaction in hypertension $[15,16]$, and wave reflection in systemic circulation [17]. Similarly the effect of aging on changing arterial compliance and left ventricular load [18-20], benefit of arterial dilation and reduced wave reflection [7], and the impact of arterial stiffening on systolic blood pressure and logical anti-hypertension treatment have been demonstrated with utilization of applanation tonometry technique [21-24]. In the present study, aortic AI as indicator of arterial stiffening is higher in the subjects with the hypertensive family history compared to subjects without the hypertensive family history after the third decade. This finding reiterates that genetic factors have an effect on the development of hypertension. Follow up these normotensive subjects whose AI is higher than the 95-confidence interval of their age group, may be helpful to assess the predictive value of aortic AI, in early development of hypertension, with implication in hypertension prevention. Early lifestyles modification and anti-hypertension treatment can be started, and hopefully hypertensive disease may be prevented.

\section{Study Limitations}

Limitations of study include relatively small sample size which has inadequate power to assess the impact of other risk factors, such as smoking, alcohol and tea drinking on AI, apart from family history. The samples were randomly collected from a large community population, making the numbers of age groups not exactly identical for comparison.

\section{References}

1. Platt R (1947) Heredity in hypertension. Quarterlly Journal of Medicine NS 16(3): 111-133. 
2. Wong CC (1997) The influence of hypertensive family history on the hypertension incidence. Chin J Cardiol 25: 46.

3. (1995) National institute on aging. Aging, vascular stiffness, and cardiovascular function: NIH Guide 24(4): 95-1074.

4. Takazawa K, O Rourke MF, Fujita M, Ranaka N, Takeda K, et al. (1996) Estimation of ascending aortic pressure from radial arterial pressure using a generalized transfer function. Z Kardiol 85(suppl3): 137-139.

5. Chen CH, Nevo E, Fetics B, Pak PH, Yin FCP, et al. (1997) Estimation of central aortic pressure waveform by mathematical transformation of radial tonometry pressure. Circulation 95(7): 1827-1836.

6. O Rourke MF (1976) Pulsatile arterial haemodyanamics in hypertension. Aust NZ J Med 6(Suppl 2): 40-48.

7. Kelly RP, Daley J, Avolio A, O Rourke MF (1989) Arterial dilation and reduced wave reflection: benefit of delevalol in hypertension. Hypertension 14(1): 14-21.

8. Kelly RP, Hayward C, Avolio AP, MO Rourke (1989) Noninvasive registration of the arterial pressure pulse. Journal of Vascular Medicine and Biology 1: 1652-1659.

9. London GM, Fuerin AP, Plannier BM, Marchais S, Benetos A, et al. (1992) Increased systolic pressure in chronic uremia: role of arterial wave reflections. Hypertension 20(1): 10-19.

10. Gareth Beevers, Gregory Y H Lip, Eoin O Brien (2001) The pathophysiology of hypertension. BMJ 322(7291): 912-916.

11. Pickering GW (1939) High blood pressure. Br Med J 1(4070): 1-3.

12. Ostfeld AM, Paul O (1963) The inheritance of hypertension. Lancet 1(7281): 75-579.

13. Feinleib M, garrison R, Borhani N (1975) Studies of hypertension in twins. Epidemiology and Control of Hypertension. In: Paul O (Edt.), Stratton Intercontinental Medical Book Corporation, New York, USA, pp: $3-17$.

ISSN: 2574-1241

DOI: 10.26717/BJSTR.2020.28.004635

Woo KS. Biomed J Sci \& Tech Res

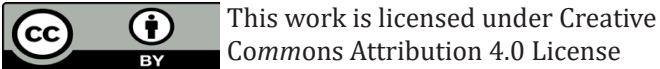

Submission Link: https://biomedres.us/submit-manuscript.php
14. Kelly RP, Gibbs H, O Rourke MF, JE Daley, K Mang, et al. (1990) Nitroglycerin has more favorable effects on left ventricular afterload than apparent from measurements of pressure in peripheral artery. Eur Heart J 11(2): 138-144.

15. 0 Rourke MF (1994) Arterial hemodynamics and ventricular-vascular interaction in hypertension. Blood pressure 3(1-2): 33-37.

16. Safar ME (2018) Arterial stiffness as a risk factor for clinical hypertension. Nat Rev Cardiol 15(2): 97-105.

17. O Rourke MF, Kelly RP (1993) Wave reflection in the systemic circulation and its implications in ventricular function. J Hypertens Suppl 11(4): 327-337.

18. Avolio AP, Chen Sg, Wang RP, Zhang CL, Li MF, et al. (1983) Effects of aging on changing arterial compliance and left ventricular load in a northern Chinese urban community. Circulation 68(1): 50-58.

19. Iketani T, Iketani Y, Takazawa K, Yamashina A (2000) The influence of the peripheral reflection wave on left ventricular hypertrophy in patients with essential hypertension. Hypertens Res 23(5): 451-458.

20. 0 Rourke MF (1990) Arterial stiffness, systolic blood pressure, and logical treatment of arterial hypertension. Hypertension 15(4): 339347.

21. O Rourke MF, Kelly RP (1993) Wave reflection in the systemic circulation and its implications in ventricular function. J Hypertens 11(4): 327-337.

22. Kelly R, Hayward C, A Avolio, O Rourke M (1989) Noninvasive Determination of Age-Related Changes in the Human Arterial Pulse. Circulation 80(6): 1652-1659.

23. Pannier BM, Guerin AP, Marchais SJ, London GM (2001) Different aortic reflection wave responses following long-term angiotensin-converting enzyme inhibition and beta-blocker in essential hypertension. Clin Exp Pharmacol Physiol 28(12): 1074-1077.

24. Mahmud A, Feely J (2000) Favorable effects on arterial wave reflection and pulse pressure amplification of adding angiotensin II receptor blockade in resistant hypertension. J Hum Hypertens 14(9): 541-546.

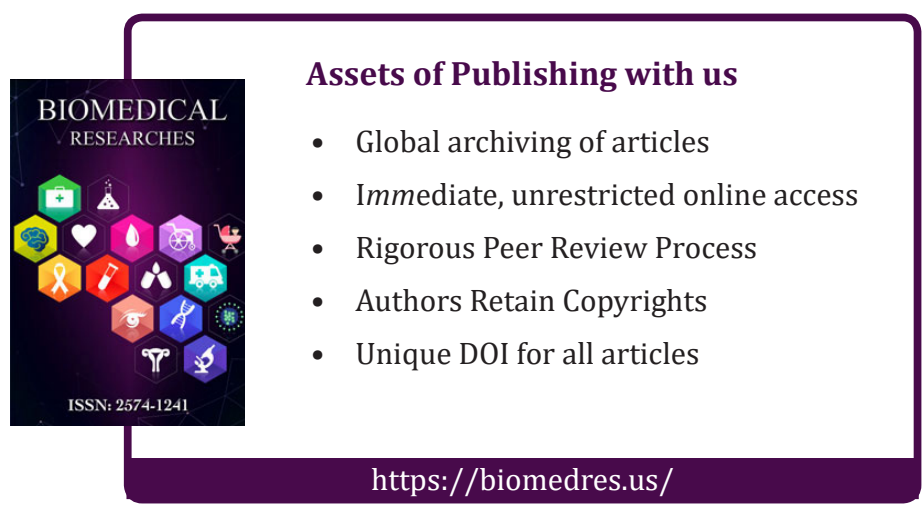

